\section{Kidney \\ Blood Pressure Research}

\title{
Determination of Procalcitonin Levels in Patients with Nephropathia Epidemica - A Useful Tool or an Unnecessary Diagnostic Procedure?
}

\author{
Joerg Latus ${ }^{\mathrm{a}} \quad$ Daniel Kitterer $^{\mathrm{a}} \quad$ Stephan Segerer $^{\mathrm{b}} \quad$ Ferruh Artunc $^{\mathrm{c}}$ \\ M. Dominik Alschera Niko Braun ${ }^{a}$
}

\begin{abstract}
aDepartment of Internal Medicine, Division of Nephrology, Robert-Bosch Hospital, Stuttgart, Germany; bDivision of Nephrology, University Hospital, Zurich, Switzerland; 'Department of Internal Medicine, Division of Endocrinology, Diabetology, Vascular Disease, Nephrology and Clinical Chemistry, University of Tuebingen, Tuebingen, Germany
\end{abstract}

\section{Key Words}

Hantavirus • Nephropathia epidemica • Procalcitonin • Risk factors • Acute kidney injury

\begin{abstract}
Background/Aims: Puumala virus causes nephropathia epidemica (NE), a milder form of hemorrhagic fever with renal syndrome that occurs in Central and Northern Europe. Several studies have sought to identify risk factors for severe NE. However, elevated procalcitonin (PCT) levels have not previously been investigated as a predictive marker for a severe course of NE. Methods: A cross-sectional prospective survey of 456 adults with serologically confirmed NE was performed. Results: PCT levels at the time of diagnosis were available for 43 out of 456 patients, and in 24 of these patients (56\%) PCT levels were elevated ("PCT positive"). C-reactive protein (CRP) levels at admission to hospital and peak CRP levels during the acute course of the disease were higher in the PCT-positive compared with the PCT-negative group $(p<0.05)$. Severe acute kidney injury (AKI) (RIFLE I and F) was present in similar numbers of PCT-positive and -negative patients $(p=0.7)$, but antibiotics were more frequently used in the PCT-positive than the PCT-negative group $(p<0.05)$. Within the PCT-positive group, PCT levels were similar among those receiving and not receiving antibiotics $(p=0.13)$, and neither the duration of hospital stay nor CRP peak levels were lower in those treated with antibiotics ( $p=0.12$ and $p=0.13$, respectively). Conclusions: Elevated PCT levels are common in patients with acute NE. There was no association between PCT levels and severity of disease, including AKI or thrombocytopenia. It is important to distinguish Puumala virus infection from other causes of AKI with thrombocytopenia. However, PCT might not be useful in differentiating hantavirus infection from bacterial infection.
\end{abstract}




\section{Kidney Blood Pressure Research}

Latus/Kitterer/Segerer et al.: Procalcitonin Levels in Nephropathia Epidemica

\section{Introduction}

Hantaviruses are enveloped RNA viruses of the family of the Bunyaviridae and pathogenic hantaviruses have rodents as their natural reservoir [1]. They can cause hemorrhagic fever with renal syndrome (HFRS) especially in Asia and Europe, and hantavirus cardiopulmonary syndrome has been described in the Americas [2-5]. Actually there is still a debate about differences between HFRS and HCPS hantavirus syndromes. Therefore, hantavirus disease should be used for all hantavirus related described symptoms [6-8]. Nephropathia epidemica (NE) is generally considered to be a milder form of HFRS caused by infection with the Puumala virus (PUUV), the main hantavirus species in Central and Northern Europe. NE is characterized by acute kidney injury (AKI) with thrombocytopenia [9]. Additionally, signs and symptoms of systemic inflammation with fever, leukocytosis, and elevated C-reactive protein (CRP) levels are a common finding in patients with acute hantavirus infection [1014]. Interleukin-10 and tumor necrosis factor (TNF)-alpha are both increased in patients with a severe course of PUUV and Dobrava infection. In addition, Koivula et al. have shown that there is a strong correlation between $\mathrm{FOXP}^{+}$regulatory $\mathrm{T}$ cells and disease severity in patients with PUUV infection [15].

The severity of PUUV infection varies from subclinical disease to rare fatalities $[16,17]$. It is therefore important to identify parameters that allow individual risk stratification at the time of diagnosis. Several studies have sought to identify risk factors for a severe course of the disease, but most variables investigated are not easily measured in everyday clinical practice $[11,14,18]$. Therefore, a more practical approach is needed. One could argue that elevated procalcitonin (PCT) levels represent more pronounced systemic inflammation, which might be associated with a more severe disease course. On the other hand, PCT levels might not be an ideal marker in viral disease as their strength is in the early diagnosis of bacterial sepsis.

Very recently Goeijenbier et al. [19] reported in a Dutch cohort of patients, with specific clinical indications for leptospirosis diagnostics, the presence of undiagnosed hantavirus cases, because acute leptospirosis and acute hantavirus infection share many clinical manifestations and certain epidemiological features. The availability of an easy accessible biomarker for the accurate diagnosis of NE would decrease the number of patients with acute hantavirus infection being misdiagnosed or missed.

The aim of the present study was to investigate the role of PCT in patients with NE and to test the hypothesis that elevated PCT levels might be associated with a worse disease course.

\section{Subjects and Methods}

Study Population

Since 2001, German laboratories have been legally obliged ( $₹ 7$ of the German Law on the Prevention and Control of Infectious Diseases) to report confirmed cases of HFRS to the local health authorities. All HFRS cases are then reported to the Robert Koch Institute in Berlin, the central federal institution responsible for disease control and prevention.

A total of 7,476 patients with serologically and clinically confirmed NE were reported to the Robert Koch Institute from 2001 to 2012 (Robert Koch Institute, Survstat, www3.rki.de/SurvStat). In cooperation with four selected local health authorities in southern Germany (Stuttgart, Boeblingen/Sindelfingen, Esslingen, and Reutlingen), we contacted 1,570 of these patients by post and asked them to attend an outpatient clinic between September 2012 and April 2013 for a follow-up examination. Overall, 456 of these patients are included in the current study.

Three patients were excluded for being younger than 18 years old at the time of NE. All patients gave written consent before participating in the study, which was approved by the ethics committee of the Ethics Commission of the State Chamber of Medicine in Baden-Wuerttemberg (Stuttgart). This study was conducted in accordance with the Declaration of Helsinki. 


\section{Kidney Bloód Pressure Research}

Latus/Kitterer/Segerer et al.: Procalcitonin Levels in Nephropathia Epidemica

Clinical Data Collection

Clinical and laboratory data during the acute course of the disease were obtained from medical reports and files. AKI was classified on the basis of the RIFLE criteria [20]: mild/moderate AKI was defined as no AKI and AKI risk (R); severe AKI was classified as RIFLE injury (I) and RIFLE failure (F). Oliguria was classified as a temporary loss of kidney function and refers to a $24-\mathrm{h}$ urine output of $<500 \mathrm{ml}$. Anuria was classified as a 24-h urine output of $<50 \mathrm{ml}$.

Patients with PCT levels $\geq 0.5 \mathrm{ng} / \mathrm{ml}$ (normal range $<0.5 \mathrm{ng} / \mathrm{ml}$ ) were classified as PCT positive, while those with PCT levels $<0.5 \mathrm{ng} / \mathrm{ml}$ were classified as PCT negative. PCT levels were not measured routinely in our study population, but rather at the treating physician's discretion (certainly due to suspected bacterial infection).

\section{Statistical Analysis}

All continuous variables were tested for normal distribution using the Kolmogorov-Smirnov test and are presented as means \pm standard deviations. The median with interquartile range is reported where the distribution was not normal. Nonparametric tests (Fisher's exact test, Mann-Whitney $U$ test) were used for statistical analysis.

Nonparametric Spearman correlation was used to analyze simple linear relationships between different variables. All $p$ values are two-sided, with significance set at $p<0.05$. All statistical analyses were performed using GraphPad statistical software (San Diego, CA, USA).

\section{Results}

PCT levels at the time of diagnosis were available for 43 of the 456 NE patients (9\%). The baseline characteristics of the study population are shown in Table 1. A total of 23 of the 43 patients (53\%) had elevated PCT levels $(\geq 0.5 \mathrm{ng} / \mathrm{ml})$ at time of admission to hospital or first contact with general practitioner/nephrologist, with a median level of $1.1 \mathrm{ng} / \mathrm{ml}$ (0.8-3.1 ng/ml). Overall, 98\% of the investigated patients had elevated CRP levels, and leukocytosis was found in $23 \%$ of patients. Median CRP levels (normal range $<0.5 \mathrm{mg} / \mathrm{dl}$ ) at hospital admission were $6.1 \mathrm{mg} / \mathrm{dl}(4.0-9.2 \mathrm{mg} / \mathrm{dl})$ in the PCT-positive group and 3.4 $\mathrm{mg} / \mathrm{dl}(2.2-6.7 \mathrm{mg} / \mathrm{dl})$ in the PCT-negative group $(\mathrm{p}<0.05)$. In addition, CRP peak levels during hospitalization were higher in the PCT-positive group $(\mathrm{p}<0.05)$. The leukocyte count, however, did not differ between the two groups at either the time of hospital admission or during the hospital stay.

Patients with elevated PCT levels were significantly older than PCT-negative patients $(\mathrm{p}<0.05)$. Time from symptom onset associated with acute hantavirus infection to hospitalization or first contact with general practitioner/nephrologist was not statistically different between the PCT-negative and PCT-positive group $(p=0.4)$. Furthermore, the duration of hospital stay was longer in the PCT-positive group, without reaching statistical significance $(p=0.46)$. A total of 17 out of 23 patients in the PCT-positive group and 19 out of 20 patients in the PCT-negative group developed AKI based on RIFLE criteria $(\mathrm{p}=0.1)$. Severe AKI (RIFLE I and F) was present in 70\% of patients in the PCT-positive group and $75 \%$ in the PCT-negative group ( $\mathrm{p}=0.7)$. Serum creatinine at time of admission or first contact with general practitioner/nephrologist and creatinine peak levels did not differ significantly between the two groups ( $\mathrm{p}=0.8$ and $\mathrm{p}=0.9$, respectively). No statistically significant correlation between PCT and serum creatinine levels could be detected (Figure 1). Severe thrombocytopenia $\left(<60 \times 10^{9} / \mathrm{l}\right)$ was present in similar proportions of patients in the PCTpositive and -negative groups.

In total, 19 out of 43 patients were treated with anti-infective agents. Antibiotic treatment was significantly more common in the PCT-positive group (14 vs. five patients, $\mathrm{p}<0.05$ ). The classes of antibiotics used during acute NE are shown in Figure 2 . Within the PCT-positive group, PCT levels did not differ between patients who did and did not receive 


\section{Kidney \\ Blood Pressure Research}

Table 1. Baseline characteristics of the study population

\begin{tabular}{|c|c|c|}
\hline Variable & PCT positive & PCT negative \\
\hline $\mathrm{n}$ & 23 & 20 \\
\hline Age at diagnosis, years* & $52 \pm 12$ & $43 \pm 16$ \\
\hline Female/male & $7 / 16$ & $9 / 11$ \\
\hline Inpatient/outpatient & $21 / 2$ & $19 / 1$ \\
\hline Time from symptom onset to hospitalization, days \# & $4(3-7)$ & $6(4-7)$ \\
\hline Duration of hospital stay, days & $10(7-12)$ & $8(5-10)$ \\
\hline Duration of fever to hospital admission, days \# & $4(2-5)$ & $5(3-7)$ \\
\hline \multicolumn{3}{|l|}{ Symptoms } \\
\hline Abdominal pain & $7 / 23$ & $8 / 20$ \\
\hline Back/flank pain & $9 / 23$ & $13 / 20$ \\
\hline Headache & $17 / 23$ & $13 / 20$ \\
\hline Visual disorders & $9 / 23$ & $5 / 20$ \\
\hline Diarrhea & $4 / 23$ & $2 / 20$ \\
\hline Nausea/vomiting & $12 / 23$ & $10 / 20$ \\
\hline \multicolumn{3}{|l|}{ Clinical signs } \\
\hline Fever & $21 / 23$ & $18 / 20$ \\
\hline Duration of fever, days & $5(4-7)$ & $5(3-8)$ \\
\hline Pathological findings on chest X-ray & $4 / 17$ & $2 / 9$ \\
\hline \multicolumn{3}{|l|}{ Abdominal ultrasound } \\
\hline Splenomegaly & $2 / 17$ & $4 / 18$ \\
\hline Hepatomegaly & $1 / 17$ & $2 / 18$ \\
\hline \multicolumn{3}{|l|}{ Laboratory findings } \\
\hline Platelets nadir, $10^{9} / 1(>150)$ & $77(58-95)$ & $103(70-147)$ \\
\hline Creatinine at admission, $\mathrm{mg} / \mathrm{dl}(0.5-1.4)$ \# & $1.4(1.0-2.5)$ & $1.9(1.3-4.4)$ \\
\hline Creatinine peak levels, mg/dl (0.5-1.4) & $3.4(2.7-6.8)$ & $4(2.5-6.7)$ \\
\hline CRP at admission, $\mathrm{mg} / \mathrm{dl}(0.1-0.4)^{*} \#$ & $6.1(4.0-9.2)$ & $3.4(2.2-6.7)$ \\
\hline CRP peak levels, mg/dl (0.1-0.4)* & $8.0(4.0-10.3)$ & $3.8(2.4-6.8)$ \\
\hline Leukocyte count, $\times 10^{9} / \mathrm{l}(3.6-10.5)$ & $4.6(4.5-5)$ & $4.6(4.2-5.0)$ \\
\hline \multicolumn{3}{|l|}{ Acute kidney injury } \\
\hline Risk & 1 & 4 \\
\hline Injury & 4 & 3 \\
\hline Failure & 12 & 12 \\
\hline \multicolumn{3}{|l|}{ Antimicrobial consumption } \\
\hline Any anti-infective agent, $\%^{*}$ & 61 & 25 \\
\hline
\end{tabular}

antibiotics ( $\mathrm{p}=0.13$ ). In addition, neither the duration of hospital stay, nor CRP peak levels were lower in those treated with antibiotics ( $p=0.12$ and $p=0.13$, respectively). All blood and urine cultures were negative during acute NE.

We compared baseline characteristics (e.g. symptoms, laboratory findings, age, creatinine, CRP levels at hospital admission) during the acute course of the disease between patients in whom PCT was tested $(\mathrm{n}=43)$ and those in whom PCT was not determined $(n=413)$. No statistically significant differences were observed between the groups except lower thrombocyte count at time of admission to hospital or first contact with general practitioner/nephrologist $(\mathrm{p}<0.05)$ and longer duration of hospital stay $(\mathrm{p}<0.05)$ in the group of patients in whom PCT was tested (table 2). 


\section{Kidney \\ Blood Pressure \\ Research}

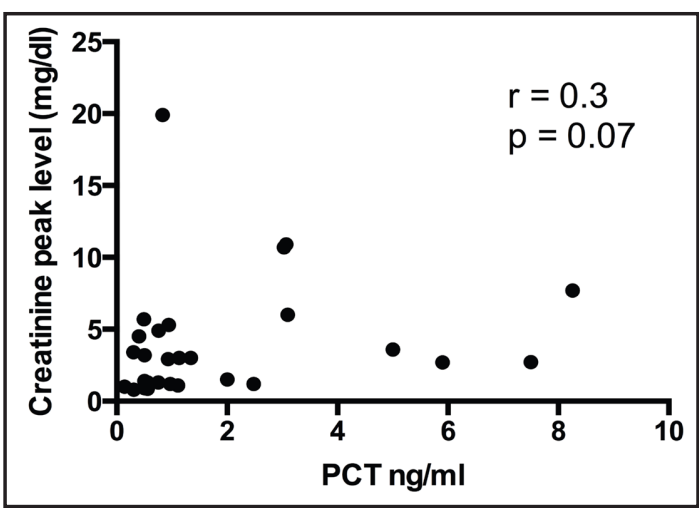

Fig. 1. Spearman correlation between procalcitonin (PCT) and peak creatinine levels in patients with acute nephropathia epidemica.

\section{Discussion}

The role of PCT as a predictive marker for a severe course of NE has not previously been investigated in a cohort of patients with acute PUUV infection. In our study, 53\% of patients had elevated PCT levels at the time of hospital admission. Neither the rate of AKI nor the severity of AKI differed between the

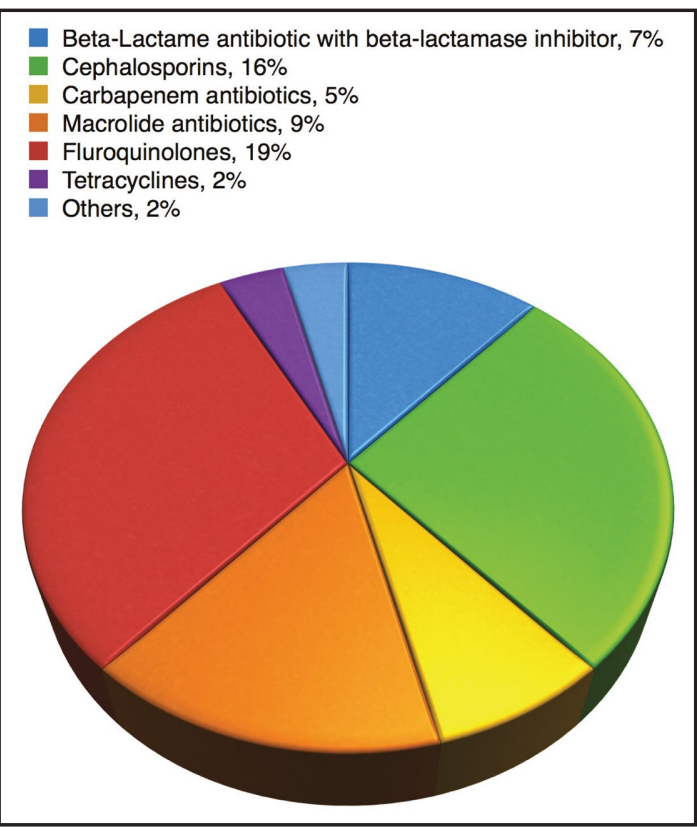

Fig. 2. Use of anti-infective agents in patients with acute Puumala virus infection. Four patients received more than one class of antibiotics during the course of disease. One patient was treated with aciclovir ("others" category).

PCT-positive and PCT-negative groups. CRP levels were elevated in almost all patients in both groups (although CRP levels were significantly higher in the PCT-positive group) and both groups had similar median leukocyte counts during the acute course of the disease. In our cohort of patients, PCT was measured at the physician's discretion (certainly due to suspected bacterial infection), which might be a selection bias in our study population. At time of admission to hospital or first contact with general practitioner/nephrologist thrombocytes were lower in the group of patients in whom PCT was tested, whereas CRP levels and severity of AKI was not different between both groups. It could be hypothesized that the low thrombocyte count might lead the physicians to test for PCT in this cohort of patients to exclude e.g. sepsis or leptospirosis.

Recently, Jereb et al. [21] investigated inflammatory markers (CRP, leukocyte count, and procalcitonin) in a retrospective cohort of 29 hantavirus patients (only 16 patients with PUUV infection and 13 patients with Dobrava virus infection) and in patients with sepsis and tick-borne encephalitis. This study confirmed an association of elevated procalcitonin with bacterial infection. However, an increased procalcitonin serum level was also found in patients with hantavirus infections, with overlapping results between viral and severe bacterial infections. In contrast to our study, the study by Jereb et al. included only 16 patients with PUUV, and disease severity (e.g. severity of AKI, severe thrombocytopenia) was not investigated with respect to elevated or normal PCT levels. Furthermore, the use of antibiotics was not reported in the Jereb et al. study.

The severity of PUUV infection varies from subclinical disease, where patients can be treated as outpatients by a general practitioner or nephrologist, to severe infection, where patients exhibit electrolyte and fluid balance disturbances due to AKI, require transient renal replacement therapy and might present hemorrhage e.g. pituitary gland or within the 


\section{Kidney \\ Blood Pressure Research}

Kidney Blood Press Res 2015;40:22-30

DOI: 10.1159/000368479

Published onIIne: January 31, 2015

(C) 2015 S. Karger AG, Base

www.karger.com/kbr

Table 2. Baseline characteristics of study population in whom PCT levels were tested or not tested

\begin{tabular}{|c|c|c|}
\hline Variable & $\begin{array}{c}\text { PCT levels } \\
\text { tested }\end{array}$ & $\begin{array}{l}\text { PCT levels } \\
\text { not tested }\end{array}$ \\
\hline $\mathrm{n}$ & 43 & 413 \\
\hline Age at diagnosis, years & $47 \pm 14$ & $48 \pm 15$ \\
\hline Time from symptom onset to hospitalization, days \# & $5(4-7)$ & $5(3-7)$ \\
\hline Duration of hospital stay, days* & $8(6-11)$ & $6(4-9)$ \\
\hline Duration of fever to hospital admission, days \# & $4(3-6)$ & $4(2-6)$ \\
\hline \multicolumn{3}{|l|}{ Symptoms } \\
\hline Abdominal pain & $15 / 43$ & $136 / 413$ \\
\hline Back/flank pain & $22 / 43$ & $285 / 413$ \\
\hline Headache & $30 / 43$ & $280 / 413$ \\
\hline Visual disorders & $14 / 43$ & $86 / 413$ \\
\hline \multicolumn{3}{|l|}{ Clinical signs } \\
\hline Fever & $39 / 43$ & $371 / 413$ \\
\hline Duration of fever, days & $5(4-7)$ & $5(3-7)$ \\
\hline Pathological findings on chest X-ray & $6 / 26$ & $43 / 187$ \\
\hline \multicolumn{3}{|l|}{ Abdominal ultrasound } \\
\hline Splenomegaly & $6 / 35$ & $60 / 263$ \\
\hline Hepatomegaly & $3 / 35$ & $14 / 263$ \\
\hline \multicolumn{3}{|l|}{ Laboratory findings } \\
\hline Platelets at admission, $10^{9} / 1(>150)^{*} \#$ & 97 (78-127) & $124(85-205)$ \\
\hline Creatinine at admission, $\mathrm{mg} / \mathrm{dl}(0.5-1.4) \#$ & $1.7(1.2-3.6)$ & $1.8(1.2-3.4)$ \\
\hline $\mathrm{CRP}$ at admission, $\mathrm{mg} / \mathrm{dl}(0.1-0.4) \#$ & $5.0(3.0-8.0)$ & $4.0(2.3-6.7)$ \\
\hline \multicolumn{3}{|l|}{ Acute kidney injury } \\
\hline Risk & 5 & 64 \\
\hline Injury & 7 & 77 \\
\hline Failure & 24 & 194 \\
\hline
\end{tabular}

gastrointestinal tract or pulmonary involvement. Several studies have sought to identify risk factors for severe disease at the time of diagnosis, but many of the variables investigated are not easily established in everyday clinical practice $[11,14,18]$. In this study, we investigated whether the routine parameter of PCT might be a useful predictive marker for a severe course of NE. Furthermore, we correlated PCT levels with CRP levels and leukocyte count to elucidate the roles of these three common inflammatory markers in NE.

Leukocyte count, but not CRP levels, during acute NE has been shown to be associated with a severe course of the disease [14]. PCT is an established marker in the differential diagnosis of infection and inflammation, and increases within 4-6 h after the initiation of bacterial infection [22-24]. Furthermore, two meta-analyses have shown that PCT is superior to CRP in the differential diagnosis of viral and bacterial infections $[25,26]$. PCT is not only induced by bacterial lipopolysaccharide but also by other mediators such as TNF [27], and TNF has been shown to be increased in patients with a severe course of PUUV infection [28]. Furthermore, it has been reported that age and sex can influence PCT levels in healthy individuals $[29,30]$.

In our study population, PCT analysis was performed to distinguish bacterial from viral infection in patients with AKI, thrombocytopenia, and systemic inflammation [differential diagnoses include leptospirosis (e.g. Weil's disease, Stuttgart disease), sepsis, autoimmune 


\section{Kidney \\ Blood Pressure Research}

disease, and thrombotic microangiopathy]. Therefore, PUUV infection should be considered even in older patients presenting with elevated PCT levels

PCT has been advocated as a superior marker for early bacterial sepsis [25], and has also been evaluated as a guide for antibiotic treatment in patients with pneumonia [31]. Thus, PCT appears to reflect bacterial disease more specifically than viral disease. PCT can also be mildly increased in viral disease per se. It is worth noting that we could not exclude bacterial coinfection or sepsis in our patients with acute NE, but both blood and urine cultures were negative in all patients. A high proportion of patients in our study population received antibiotics during acute NE, and antibiotics were more frequently used in the PCT-positive compared with the PCT-negative group. Remarkably, within the PCT-positive group, the duration of hospital stay, peak CRP levels, and PCT levels were similar among those treated and not treated with antibiotics. Whether elevated PCT levels might lead to unnecessary antibiotic treatment in a proportion of patients with acute hantavirus infection has to tested in a larger cohort of patients.

This study has several limitations. First, we performed a retrospective study of medical case reports, with all known associated limitations. In addition, the study design may have resulted in selection bias, with a greater number of patients with severe NE included (approximately one third of NE occurs with typical clinical signs, resulting in a high underreporting especially in younger patients with a mild course of the disease). As mentioned previously in the discussion section, thrombocytes were lower in the group of patients in whom PCT was tested, which might lead to a selection bias.

Furthermore, patients in the PCT-positive group were older than those in the PCTnegative group; and bacterial coinfection could not be definitely excluded in our study population. Further prospective studies including larger cohorts of patients are warranted to, for example, investigate the role of elevated PCT levels with respect to the disease course and investigate "new" biomarkers, such as TNF-related apoptosis-inducing ligand (TRAIL), to differentiate NE from bacterial infection. This would be very helpful for clinicians in everyday clinical practice. Whether elevated PCT levels at the time of diagnosis were related to disease management in a cohort of patients has to be investigated in a prospective cohort study.

\section{Conclusion}

Elevated PCT levels are common in patients with acute NE. There was no association between PCT levels and disease severity, including major findings such as AKI or thrombocytopenia. The separation of PUUV infection from other causes of AKI with thrombocytopenia is important. However, PCT might not be useful in differentiating NE from bacterial infection.

\section{Disclosure Statement}

The authors of this manuscript state that they do not have any conflict of interests and nothing to disclose.

\section{Acknowledgments}

None. 


\section{Kidney \\ Blood Pressure Research}

\begin{tabular}{|c|c|}
\hline Kidney Blood Press Res 201 & \\
\hline $\begin{array}{l}\text { DOI: } 10.1159 / 000368479 \\
\text { Publisned onllne: January } 31,2015\end{array}$ & $\begin{array}{l}\text { (C) } 2015 \text { S. Karger AG, Basel } \\
\text { www.karger.com/kbr }\end{array}$ \\
\hline
\end{tabular}

\section{References}

1 Schmaljohn CS, Dalrymple JM: Analysis of Hantaan virus RNA: evidence for a new genus of bunyaviridae. Virology 1983;131:482-491.

- Kruger DH, Ulrich R, Lundkvist AA: Hantavirus infections and their prevention. Microbes Infect 2001;3:1129-1144.

- Lee HW, van der Groen G: Hemorrhagic fever with renal syndrome. Prog Med Virol 1989;36:62-102.

4 Mertz GJ, Hjelle B, Crowley M, Iwamoto G, Tomicic V, Vial PA: Diagnosis and treatment of new world hantavirus infections. Curr Opin Infect Dis 2006;19:437-442.

5 Peters CJ, Simpson GL, Levy H: Spectrum of hantavirus infection: hemorrhagic fever with renal syndrome and hantavirus pulmonary syndrome. Annu Rev Med 1999;50:531-545.

6 Goeijenbier M, Wagenaar J, Goris M, Martina B, Henttonen H, Vaheri A, Reusken C, Hartskeerl R, Osterhaus A, Van Gorp E: Rodent-borne hemorrhagic fevers: under-recognized, widely spread and preventable epidemiology, diagnostics and treatment. Crit Rev Microbiol 2013;39:26-42.

7 Rasmuson J, Andersson C, Norrman E, Haney M, Evander M, Ahlm C: Time to revise the paradigm of hantavirus syndromes? Hantavirus pulmonary syndrome caused by European hantavirus. Eur J Clin Microbiol Infect Dis 2011;30:685-690.

8 Clement J, Maes P, Lagrou K, Van Ranst M, Lameire N: A unifying hypothesis and a single name for a complex globally emerging infection: hantavirus disease. Eur J Clin Microbiol Infect Dis 2012;31:1-5.

-9 Krautkramer E, Zeier M, Plyusnin A: Hantavirus infection: an emerging infectious disease causing acute renal failure. Kidney Int 2013;83:23-27.

10 Mustonen J, Brummer-Korvenkontio M, Hedman K, Pasternack A, Pietila K, Vaheri A: Nephropathia epidemica in Finland: a retrospective study of 126 cases. Scand J Infect Dis 1994;26:7-13.

11 Outinen TK, Makela SM, Ala-Houhala IO, Huhtala HS, Hurme M, Paakkala AS, Porsti IH, Syrjanen JT, Mustonen JT: The severity of Puumala hantavirus induced nephropathia epidemica can be better evaluated using plasma interleukin-6 than C-reactive protein determinations. BMC Infect Dis 2010;10:132.

12 Vaheri A, Strandin T, Hepojoki J, Sironen T, Henttonen H, Makela S, Mustonen J: Uncovering the mysteries of hantavirus infections. Nat Rev Microbiol 2013;11:539-550.

13 Latus J, Fritzenkotter M, Schmidt-Chanasit J, Tenner-Racz K, Leibold T, Kimmel M, Ott G, Ting E, Alscher MD, Braun N: Hantavirus and acute appendicitis--the diagnosis behind the diagnosis? J Clin Virol 2012;53:156158.

14 Libraty DH, Makela S, Vlk J, Hurme M, Vaheri A, Ennis FA, Mustonen J: The degree of leukocytosis and urine GATA-3 mRNA levels are risk factors for severe acute kidney injury in Puumala virus nephropathia epidemica. PLoS One 2012;7:e35402.

15 Koivula TT, Tuulasvaara A, Hetemaki I, Makela SM, Mustonen J, Sironen T, Vaheri A, Arstila TP: Regulatory T cell response correlates with the severity of human hantavirus infection. J Infect 2014;68:387-394.

16 Hjertqvist M, Klein SL, Ahlm C, Klingstrom J: Mortality rate patterns for hemorrhagic fever with renal syndrome caused by Puumala virus. Emerg Infect Dis 2010;16:1584-1586.

17 Makary P, Kanerva M, Ollgren J, Virtanen MJ, Vapalahti O, Lyytikainen O: Disease burden of Puumala virus infections, 1995-2008. Epidemiol Infect 2010;138:1484-1492.

18 Outinen TK, Kuparinen T, Jylhava J, Leppanen S, Mustonen J, Makela S, Porsti I, Syrjanen J, Vaheri A, Hurme M: Plasma cell-free DNA levels are elevated in acute Puumala hantavirus infection. PLoS One 2012;7:e31455.

19 Goeijenbier M, Hartskeerl RA, Reimerink J, Verner-Carlsson J, Wagenaar JF, Goris MG, Martina BE, Lundkvist A, Koopmans M, Osterhaus AD, van Gorp EC, Reusken CB: The hanta hunting study: underdiagnosis of Puumala hantavirus infections in symptomatic non-travelling leptospirosis-suspected patients in the Netherlands, in 2010 and April to November 2011. Euro Surveill 2014;19

20 Bellomo R, Ronco C, Kellum JA, Mehta RL, Palevsky P: Acute renal failure - definition, outcome measures, animal models, fluid therapy and information technology needs: the Second International Consensus Conference of the Acute Dialysis Quality Initiative (ADQI) Group. Crit Care 2004;8:R204-212.

21 Jereb M, Lunacek NK, Kotar T, Saksida A, Petrovec M, Avsic-Zupanc T: Procalcitonin in hantavirus infections. Scand J Clin Lab Invest 2011;71:287-291. 


\section{Kidney \\ Blood Pressure Research}

Kidney Blood Press Res 2015;40:22-30

DOI: 10.1159/000368479

Published onlıne: January 31, 2015

(C) 2015 S. Karger AG, Basel

www.karger.com/kbr

22 Gilbert DN: Use of plasma procalcitonin levels as an adjunct to clinical microbiology. J Clin Microbiol 2010;48:2325-2329.

-23 Gendrel D, Raymond J, Coste J, Moulin F, Lorrot M, Guerin S, Ravilly S, Lefevre H, Royer C, Lacombe C, Palmer P, Bohuon C: Comparison of procalcitonin with C-reactive protein, interleukin 6 and interferonalpha for differentiation of bacterial vs. viral infections. Pediatr Infect Dis J 1999;18:875-881.

-24 Prat C, Dominguez J, Rodrigo C, Gimenez M, Azuara M, Jimenez O, Gali N, Ausina V: Procalcitonin, C-reactive protein and leukocyte count in children with lower respiratory tract infection. Pediatr Infect Dis J 2003;22:963-968.

25 Simon L, Gauvin F, Amre DK, Saint-Louis P, Lacroix J: Serum procalcitonin and C-reactive protein levels as markers of bacterial infection: a systematic review and meta-analysis. Clin Infect Dis 2004;39:206-217.

26 Yo CH, Hsieh PS, Lee SH, Wu JY, Chang SS, Tasi KC, Lee CC: Comparison of the test characteristics of procalcitonin to C-reactive protein and leukocytosis for the detection of serious bacterial infections in children presenting with fever without source: a systematic review and meta-analysis. Ann Emerg Med 2012;60:591-600.

-27 Nijsten MW, Olinga P, The TH, de Vries EG, Koops HS, Groothuis GM, Limburg PC, ten Duis HJ, Moshage H, Hoekstra HJ, Bijzet J, Zwaveling JH: Procalcitonin behaves as a fast responding acute phase protein in vivo and in vitro. Crit Care Med 2000;28:458-461.

28 Saksida A, Wraber B, Avsic-Zupanc T: Serum levels of inflammatory and regulatory cytokines in patients with hemorrhagic fever with renal syndrome. BMC Infect Dis 2011;11:142.

29 Cotoi OS, Manjer J, Hedblad B, Engstrom G, Melander O, Schiopu A: Plasma procalcitonin is associated with all-cause and cancer mortality in apparently healthy men: a prospective population-based study. BMC Med 2013;11:180.

-30 Schiopu A, Hedblad B, Engstrom G, Struck J, Morgenthaler NG, Melander 0: Plasma procalcitonin and the risk of cardiovascular events and death: a prospective population-based study. J Intern Med 2012;272:484491.

-31 Schuetz P, Christ-Crain M, Thomann R, Falconnier C, Wolbers M, Widmer I, Neidert S, Fricker T, Blum C, Schild U, Regez K, Schoenenberger R, Henzen C, Bregenzer T, Hoess C, Krause M, Bucher HC, Zimmerli W, Mueller B, Pro HSG: Effect of procalcitonin-based guidelines vs standard guidelines on antibiotic use in lower respiratory tract infections: the ProHOSP randomized controlled trial. JAMA 2009;302:1059-1066. 